\section{Flu jabs in general practice}

I have just finished our first flu jab clinic of the year. I have enjoyed the banter from the patients; you should line us up like they used to in the army' and other such comments. I have enjoyed the competition with the other clinicians; who can give the most in the time! Most of all I have enjoyed the essence of general practice. Seeing my patients a year on, I notice which patients are well and which ones are not moving as well, or who seem a little frailer.

So why am I writing this, having been one of the quiet GP partners trying to keep going in increasingly troubled times? I am writing this as, in their great wisdom, NHSE and PHE felt that pharmacies should get in on the flu jabs. I am sure this is appropriate to increase the uptake, but the knock-on effect of poorly thought-through plans are beginning to show.

NHSE insist that we order enough flu jabs for our at-risk population. Fine, but then the pharmacy receives their flu jabs 3 weeks before us from the producers as the retailers can place larger orders. Pharmacies in our area had a 3-week head-start on us. Our nurses must have annual immunisation update training. Do the pharmacist and technicians? We have full resuscitation equipment on site. Do pharmacies? The pharmacy has to inform us that they have given the flu jab but not the batch number or expiry date. So, if they have a reaction, which of course we will have to see, we do not have this information to report the adverse reaction. And to add insult to injury the pharmacies get paid $96 \mathrm{p}$ more for each flu jab.

If we make a loss this year, we will not be sacrificing our Saturday mornings that are not being used for extended access, we will not be signing the flu DES, and the losers will be the patients. I am sure too that the pharmacist will not be doing home visits to the house bound and I will lose my precious time for assessing whether my patients are ageing well or need some extra vigilance in the year to come.

Shame on the RCGP and the BMA for allowing the further disintegration of general practice. Sometimes the small things are just as important as the large issues.
Ruth Clayton,

GP, Dodington Surgery, Whitchurch.

Email: ruth.claytonanhs.net

DOI: https://doi.org/10.3399/bjgp19X706181

\section{Effect of weather on GP home visits}

This was a good study; however, to play devil's advocate, I wonder if it would have been worth exploring or discussing the study's limitations in more detail. For instance, this study is based on data not from traditional general practice, which is probably still by far and large the major provider of GP home visiting, but from a service that appears to be resourced and designed for in-hours visiting and might not have the competing priorities that the average GP surgery might have.

A future study might want to look at total visit requests in traditional general practice land bespoke services like this one), and the proportion that were responded to by visits, and track that proportion as a priority compared with net numbers, over the seasons, since overall visit requests land demand for competing everyday practice tasks, such as prescription and document processing workloads) may be lower in summer in any case.

Anirban Gupta,

GP, Epsom Health and Care, Surrey.

Email: anirdoclahotmail.com

\section{REFERENCE}

1. Oyawoye $\mathrm{O}$, Marston L, Jones M. Effect of weather on GP home visits: a cross-sectional study. $\mathrm{Br}$ J Gen Pract 2019; DOI: https://doi.org/10.3399/ bjgp19X702257.

DOI: https://doi.org/10.3399/bjgp19X706193

\section{Author response}

Thank you to Gupta for his critique of our paper with points that are well made. In the online full-text version, we were able to discuss the strengths and weaknesses of our methods and analysis in greater detail.' Delegated home-visiting services are indeed still relatively unusual and we agree that the bulk of the home visits are made by GPs in GMS/PMS models of service with all the competing pressures that Gupta describes. What the Herts Urgent Care (HUC) model did was to give us a reliable method to link a specific visit request to a geographical location and date, so we could make a reliable link to weather data, which is both time and geographically dependent and highly variable, as every GP with wet shoes knows. With the plethora of GP IT systems and GDPR regulations, linking these data would have been very difficult to do for specific practices, CCGs, or indeed regionally.

The temporal link between season of the year and reduced visiting in the summer was found in our study (see Table 1) but we were able to drill down further and show that there were no clinically important differences on cold and wet days. The study was originally called 'GPs get there whatever the weather', which could possibly be justified from our data. A better understanding of the vital role home visiting in primary care plays is essential as it is the clinical 'glue' holding together community services that enables frail and older people to receive care in their home, that if it were not provided would rapidly overwhelm NHS services.

Melvyn Jones,

GP and Associate Professor, UCL.

Email: melvyn.jones(aucl.ac.uk

\section{REFERENCE}

1. Oyawoye $O$, Marston $L$, Jones M. Effect of weather on GP home visits: a cross-sectional study. $\mathrm{Br}$ J Gen Pract 2019; DOI: https://doi.org/10.3399/ bjgp19X702257.

\section{Undergraduate exposure to GPs with Extended Roles}

GP with extended roles (GPwERs) may be 